\title{
Optimization Carbopol And Glycerol As Basis Of Hand Gel Antiseptics Extract Ethanol Ceremai Leaf (Phyllantus Acidus (L.) Skeels) With Simplex Lattice Design
}

\section{Optimasi Karbopol Dan Gliserol Sebagai Basis Gel Antiseptik Tangan Ekstrak Etanol Daun Ceremai (Phyllantus Acidus (L.) Skeels) dengan Metode Simplex Lattice Design}

\author{
Dwi Saryanti $^{1^{*}}$ dan Izzatun Ni'mah Zulfa ${ }^{2}$ \\ 1 Prodi D3 Farmasi Stikes Nasional Surakarta, Jl. Yos Sudarso No 338 Surakarta; \\ dwisary_dws@yahoo.com \\ 2 Prodi D3 Farmasi Stikes Nasional Surakarta, Jl. Yos Sudarso No 338 Surakarta; \\ *email korespondensi : dwisary_dws@yahoo.com
}

\begin{abstract}
Ceremai leaf (Phyllanthus acidus (L.) Skeels) is the one of the potential plant which contain flavonoid that had antibacterial activity. Carbopol is a gelling agent that is easily dispersible in water and provide consistency to the gel, while the glycerin is a humectant that can improve the softness of the gel. Carbopol can provide viscosity / hardness in the gel it is necessary to combine with glycerin to soften the gel and the increase of the spread The aims of this research to know the optimum composition from carbopol and gliserol in antiseptic gel formulation of ceremai leaf ethanol extract by Simplex Lattice Design (SLD). The method of extraction used maseration method with ethanol $70 \%$ solvent. extract made of gel with components carbopol 940(0-100\%) and glycerin(0-100\%) with respond criteria physical properties such as $\mathrm{pH}$, spreadability, sticking and protection power. The optimum formulated based on Simplex Lattice Design was the combination of carbopol $50 \%$ : glycerol $50 \%$. Optimum results are obtained gel has a good physical properties. The test results showed that the effectiveness of antiseptic hand gels have generated a good antiseptic. Acceptability test results showed that the gel can be accepted by society.
\end{abstract}

Keywords: extract ethanol of ceremai leaf, carbopol, glycerol, Simplex Lattice Design

Abstrak: Daun ceremai (Phyllanthus acidus (L.) Skeels) merupakan salah satu sumber daya hayati yang sangat potensial yang mengandung senyawa flavonoid yang berperan dalam aktivitas antibakteri. Karbopol merupakan basis gel yang bersifat mudah terdis- 
Persi dalam air dan memberikan kekentalan pada gel, sedangkan gliserin merupakan humektan yang dapat meningkatkan kelembutan gel. Karbopol dapat memberikan kekentalan / kekerasan pada sediaan gel maka perlu dikombinasi dengan gliserin yang dapat melunakkan sediaan gel, dan meningkatkan daya sebar. Tujuan dari penelitian ini adalah untuk mengetahui komposisi optimum dari karbopol dan gliserol dalam formulasi gel antiseptik ekstrak etanol daun ceremai menggunakan metode Simplex Lattice Design (SLD). Ekstraksi daun ceremai menggunakan metode maserasi dengan pelarut etanol $70 \%$. Optimasi sediaan gel menggunakan basis karbopol (0-100\%) dan gliserin (0-100\%) dengan parameter respon sifat fisik yaitu $\mathrm{pH}$, daya sebar, daya lekat dan daya proteksi. Formula gel optimum berdasarkan Simplex Lattice Design adalah kombinasi karbopol $50 \%$ : gliserol $50 \%$. Hasil gel optimum yang didapatkan memiliki kualitas fisik yang baik dan memenuhi syarat sediaan gel. Hasil uji efektivitas menunjukkan bahwa gel antiseptik tangan yang dihasilkan mempunyai antiseptik yang baik. Hasil uji aseptabilitas menunjukkan bahwa gel dapat diterima oleh masyarakat.

Kata Kunci : ekstrak etanol daun cermai, karbopol, gliserol, Simplex Lattice Design

\section{Pendahuluan}

Kekayaan jenis tanaman yang tumbuh di Indonesia sangat berlimpah, termasuk di dalamnya adalah tanaman yang dapat dimanfaatkan untuk tujuan pengobatan (Mursito, 2000). Penggunaan bahan alam semakin meningkat di masyarakat karena bahan alam mudah diperoleh, harganya relatif lebih murah dan efek sampingnya juga kecil.

Salah satu tumbuhan yang mempunyai aktivitas antibakteri adalah daun jambu ceremai (Phyllantus acidus (L.) Skeels.). Menurut Prasetya (2010) tanaman ceremai mempunyai khasiat sebagai hepatoprotektor, antibakteri, dan antijamur. Penelitian sebelumnya (Budiyanti, 2009) menunjukkan bahwa ekstrak etanol daun ceremai mengandung senyawa polifenol serta mempunyai aktivitas antibakteri terhadap Staphylococcus aureus dan Escherichia coli dengan Kadar Bunuh Minimal (KBM) S. Aureus dan E. Coli berturut-turut sebesar 0,5\% b/v dan 6\% b/v.

Formulasi ekstrak daun cermai menjadi sediaan gel antiseptik tangan dipilih karena mampu memberikan efek dingin, menyejukkan, melembabkan, mudah berpenetrasi pada kulit sehingga praktis, cepat penggunaannya dan mempunyai kemampuan antiseptik yang baik. Penelitian yang dilakukan untuk memperoleh komposisi basis karbopol dan gliserol dalam formula gel yang mempunyai efektivitas, kualitas fisik dan aseptabilitas yang optimal dengan menggunakan dengan menggunakan metode Simplex Lattice Design (SLD).

Metode Simplex Lattice Design digunakan untuk optimasi formula karena dapat menghasilkan formula optimal dengan jumlah bahan berbeda yang konstan (Bolton dan Bon, 1997). Dalam penelitian digunakan untuk menentukan formula optimal campuran HPMC dan gliserol dalam campuran basis gel antiseptik. Metode SLD berguna untuk memprediksi respon dalam formulasi sediaan. 


\section{Bahan dan Metode}

\subsection{Bahan}

Daun ceremai (Phyllanthus acidus L) diperoleh dari Kembangan, Sukoharjo, Jawa Tengah. Etanol $70 \%$, karbopol 940, gliserol, trietanolamin, nipagin, corigen odoris, akuades, parafin solid, phenolphtalein, $\mathrm{NaOH}$, media nutrien agar. Bahan diperoleh dari Bratacem dengan derajat teknis.

2.2. Alat

Waterbath, blender (Sharp), timbangan analitik ( (Arcis AD-600), cawan penguap, oven(Memmert), mortir dan stamfer, alat-alat gelas (pyrex), incubator (Memmert), alat uji homogenitas, alat uji daya lekat, alat uji daya proteksi, alat uji daya sebar.

\subsection{Metode}

\subsubsection{Ekstraksi bahan}

Ekstraksi dilakukan dengan cara maserasi. 1 bagian serbuk kering di maserasi dengan 7,5 bagian etanol $70 \%$ selama 5 hari dengan sesekali pengadukan). Maserat yang diperoleh diuapkan menggunakan rotary evaporator, dan dipekatkan diatas waterbath sampai diperoleh ekstrak kental. Rendemen dihitung dari $\frac{\text { bobot ekstrak }}{\text { bobot serbuk }} \times 100 \%$

\subsubsection{Optimasi formula gel}

Optimasi formula gel menggunakan basis karbopol 0-100\% b/b dan gliserol 0-100\% b/b. Optimasi dilakukan dengan metode Simplex Lattice Design 2 variabel dengan parameter yang diamati adalah uji $\mathrm{pH}$, daya sebar, daya lekat dan daya proteksi. Uji daya lekat dengan meletakkan $0,5 \mathrm{~g}$ sediaan di atas obyek glass yang telah ditentukan luasnya pada alat uji. Obyek glass yang lain diletakkan di atas sediaan tersebut, kemudian diberikan beban seberat 0,5 kg selama 5 menit. Beban seberat $80 \mathrm{~g}$ dilepaskan sehingga menarik obyek glass bagian bawah. Waktu yang diperlukan hingga kedua obyek glass terlepas dicatat. Uji daya sebar dengan menimbang Sebanyak 0,5 g sediaan dan diletakkan di atas kaca kemudian ditutup dengan kaca penutup yang telah ditimbang sebelumnya. Didiamkan 1 menit dan diukur diameter gel yang menyebar. Dilakukan dengan penambahan beban $50 \mathrm{~g}$, beban $100 \mathrm{~g}$, beban $150 \mathrm{~g}$, dibiarkan selama 1 menit tiap penambahan beban dan diukur diameter gel yang menyebar. Uji daya proteksi dengan membasahi Sepotong kertas saring dengan ukuran $10 \mathrm{x}$ $10 \mathrm{~cm}$ dengan larutan phenophthalein (PP) sebagai indikator kemudian dikeringkan. Kertas tersebut diolesi dengan 0,5 g sediaan pada salah satu permukaan secara merata. Kertas saring dipotong dengan ukuran 2,5 x 2,5 cm dengan 1 tetes $\mathrm{NaOH}$ encer $\mathrm{P}(4 \%)$ atau $\mathrm{NaOH} \mathrm{LP}$, diamati timbulnya noda kemerahan pada kertas yang dibasahi dengan larutan phenophthalein. Waktu yang diperlukan mulai kertas ditetesi $\mathrm{NaOH}$ encer $\mathrm{P}$ hingga warna merah muncul dicatat.

\subsubsection{Pembuatan Gel}


Karbopol dikembangkan dalam setengah bagian air panas kemudian diaduk hingga larut. Ekstrak etanol daun ceremai ditambahkan gliserol, nipagin, dimasukkan ke dalam karbopol. Akuades ditambahkan hingga 25 g. TEA dan corigens odoris ditambahkan, kemudian diaduk sampai homogen

\subsubsection{Verifikasi formula optimal}

Formula gel optimal yang diperoleh dari metode Simplex Lattice Design dilakukan uji kualitas fisik yang meliputi uji homogenitas, $\mathrm{pH}$, daya sebar, daya lekat dan daya proteksi. Hasil pengujian dibandingkan dengan hasil prediksi dari software.

\subsubsection{Uji efektivitas gel formula optimal}

Uji efektivitas dengan kontak sidik ibu jari ke dalam media nutrien agar. Gel sebanyak 0,5 $\mathrm{ml}$ diteteskan ke tangan yang bersih, diratakan dan didiamkan selama 1 menit dan dilakukan kontak dengan media. Media diinkubasi selama 24 jam pada suhu $37^{\circ} \mathrm{C}$. Setelah diinkubasi, jumlah koloni bakteri dihitung.

\subsubsection{Uji aseptabilitas}

Uji aseptabilitas pemakaian sediaan gel dilakukan terhadap 20 responden sehingga setiap responden wanita berusia 20-30 tahun. Responden dalam keadaan sehat serta tidak mempunyai penyakit kulit. Sediaan gel digunakan dengan cara mengoleskan $0,5 \mathrm{~g}$ gel pada telapak tangan responden, kemudian didiamkan selama 1 menit. Penilaian oleh responden dilakukan dengan mengisi kuisioner yang telah disediakan.

\section{Hasil dan Pembahasan}

Proses ekstraksi dilakukan dengan cara maserasi karena kandungan senyawa flavonoid dalam daun cermain yang berperan sebagai antibakteri dapat tersari maksimal dan tidak rusak oleh pemanasan. Flavonoid bersifat polar sehingga penyari yang digunakan yaitu etanol $70 \%$ yang bersifat polar, hal ini sesuai dengan prinsip like dissolve like yaitu senyawa polar dapat larut dalam pelarut polar dan senyawa non polar dapat larut dalam pelarut non polar (Hidayati dkk, 2012). Rendemen yang diperoleh adalah $12.68 \%$.

\subsection{Optimasi Formula Gel}

Penentuan formula optimal dengan menggunakan metode Simplex Lattice Design (SLD). Data hasil uji kualitas fisik yang diperoleh dari 3 kali pengujian pada rancangan formula A yaitu karbopol : gliserol (100\%: $0 \%$ ), formula B yaitu karbopol : gliserol (0 \%: $100 \%)$, dan formula C yaitu karbopol : gliserol (50\%:50\%). Data hasil uji kualitas fisik yang dimasukkan sebagai respon antara lain $\mathrm{pH}$, daya sebar, daya lekat, dan daya proteksi.

pH sediaan gel sebaiknya disesuaikan dengan $\mathrm{pH}$ kulit yaitu 4,5-6,5 untuk menghindari terjadinya iritasi pada saat penggunaan (Aponno dkk, 2014). Berdasarkan parameter pengujian pH diperoleh persamaan dari metode Simplex Lattice Design yaitu persamaan 1. 


$$
\mathrm{Y}=4,00(\mathrm{~A})+\mathbf{6 , 0 0}(\mathrm{B})
$$

Keterangan: $\mathrm{Y}=$ pH, $\mathrm{A}=$ komposisi karbopol, $\mathrm{B}=$ komposisi gliserol

Persamaan (1) dapat memberi informasi mengenai pengaruh masing-masing komponen terhadap sediaan gel. Pengaruh positif (meningkatkan $\mathrm{pH}$ ) diberikan oleh komponen karbopol dan gliserol. Koefisien yang lebih besar menunjukkan komponen yang lebih dominan terhadap respon (Ahmad dkk., 2014).

Daya sebar menunjukkan kemampuan gel untuk menyebar ketika digunakan. Daya sebar 5-7 cm menunjukkan konsistensi semisolid yang sangat nyaman dalam penggunaan (Garg dkk, 2002). Berdasarkan parameter pengujian daya sebar diperoleh persamaan (2) dari metode Simplex Lattice Design berikut:

$$
\mathrm{Y}=\mathbf{4 , 9 2}(\mathrm{A})+\mathbf{9 , 0 8}(\mathrm{B})
$$

\section{Keterangan: $\mathrm{Y}=\mathbf{p H}, \mathrm{A}=$ komposisi karbopol, $\mathrm{B}=$ komposisi gliserol}

Persamaan (2) dapat memberi informasi mengenai pengaruh masing-masing komponen terhadap sediaan gel. Pengaruh positif (meningkatkan daya sebar) diberikan oleh komponen karbopol dan gliserol.

Daya lekat menunjukkan kemampuan sediaan bertahan pada kulit yang berkaitan dengan ketahanan zat aktif pada kulit. Berdasarkan parameter daya lekat sediaan gel diperoleh persamaan (3) dari metode Simplex Lattice Design berikut:

$$
\mathrm{Y}=\mathbf{0 , 2 9}(\mathrm{A})+\mathbf{0 , 2 0}(\mathrm{B})
$$

\section{Keterangan: $\mathrm{Y}=$ pH, A = komposisi karbopol, $\mathrm{B}=$ komposisi gliserol}

Persamaan (3) dapat memberi informasi mengenai pengaruh masing-masing komponen terhadap sediaan gel. Pengaruh positif (meningkatkan daya lekat) diberikan oleh komponen karbopol dan gliserol.

Pengujian daya proteksi dapat mengetahui kemampuan proteksi sediaan gel terhadap pengaruh keadaan lingkungan sekitar seperti $\mathrm{pH}$, suhu. Berdasarkan parameter daya proteksi gel diperoleh persamaan (4) dari metode Simplex Lattice Design berikut:

$$
\mathrm{Y}=0,22(\mathrm{~A})+\mathbf{0 , 1 8}(\mathrm{B})+\mathbf{0 , 1 9}(\mathrm{A})(\mathrm{B})
$$

\section{Keterangan: $\mathrm{Y}=$ pH, $\mathrm{A}=$ komposisi karbopol, $\mathrm{B}=$ komposisi gliserol}

Persamaan (4) dapat memberi informasi mengenai pengaruh masing-masing komponen terhadap sediaan gel. Pengaruh positif (meningkatkan daya proteksi) diberikan oleh komponen karbopol dan gliserol.

Optimasi dilakukan pada karbopol dan gliserin yang diatur dalam rentangnya masing-masing minimal $0 \%$ dan maksimal $100 \%$. Respon daya sebar diatur dalam rentang 5-7 cm dengan 
tujuan kemampuannya menyebar pada kulit baik, dimana hal ini berkaitan dengan daya distribusi zat aktif yang terkandung di dalam sediaan. Respon daya lekat diminimalkan agar gel antiseptik yang dihasilkan tidak terlalu lengket di kulit dan nyaman digunakan. Respon daya proteksi dimaksimalkan agar sediaan gel yang dihasilkan dapat memberikan proteksi yang maksimal saat digunakan. Respon $\mathrm{pH}$ diatur dalam rentang 4,5 - 6,5 sehingga gel yang dihasilkan aman dan tidak menimbulkan iritasi di kulit.

Nilai desirability dipengaruhi oleh jumlah respon dan target yang ingin dicapai untuk memperoleh formula optimum (Engelina, 2013). Formula yang disarankan dari Design Expert 7.1.5 adalah SNEDDS dengan komposis karbopol 50\% dan gliserol 50\% dengan nilai desirability 0,624. Formula ini diprediksi mempunyai $\mathrm{pH} 5$, daya sebar $7 \mathrm{~cm}$, daya lekat 0,25 detik dan daya proteksi 0,25 detik. Hasil yang diperoleh melalui observasi pada formula tersebut menghasilkan $\mathrm{pH} 5 \pm 0$, daya sebar $6,06 \pm 0,03$, daya lekat sebesar $0,26 \pm 0,03$ detik dan daya proteksi $0,25 \pm 0,025$. Oleh karena itu persamaan yang diperoleh masih dianggap cukup baik untuk menentukan formula optimal.

\subsection{Pengujian efektivitas sediaan gel formula optimal}

Pengujian ini bertujuan untuk mengetahui apakah ekstrak etanol daun ceremai dapat berperan sebagai antiseptik jika diformulasikan dalam sediaan gel. Hasil uji efektivitas gel menunjukkan bahwa gel ekstrak daun ceremai mampu menghambat pertumbuhan bakteri seperti terlihat pada tabel 1.

Tabel 1 menunjukkan efektivitas gel sebagai antiseptik dari gel ekstrak daun ceremai. Gel ekstrak daun ceremai menghasilkan jumlah koloni yang tumbuh lebih sedikit dibanding gel tanpa ekstrak. Hal ini dikarenakan bahan aktif ekstrak etanol daun ceremai yang memiliki kandungan senyawa seperti flavonoid dan fenol yang berperan sebagai antimikroba dengan mekanisme merusak membran sel bakteri sehingga bakteri mengalami lisis dan mati (Hidayati dkk, 2012).

Hasil pengujian aktivitas penghambatan terhadap bakteri Staphylococcus aureus dapat dilihat pada gambar 1. Dari gambar dapat terlihat bahwa pertumbuhan bakteri menjadi terhambat dilihat dari koloni yang lebih sedikit gel tanpa penambahan ekstrak (gambar 2.)

Basis gel mungkin dapat menghambat pelepasan senyawa metabolit sekunder dari ekstrak etanol daun ceremai (flavonoid, saponin dan tanin) untuk terlepas ke dalam media Nutrient Agar. Hal ini karena kelarutan ekstrak etanol daun ceremai dan basis gel sama-sama bersifat polar sehingga keduanya akan saling terikat kuat satu sama lain dan efek antiseptiknya menjadi tidak optimal. Gel antiseptik ekstrak masih terdapat pertumbuhan bakteri karena konsentrasi ekstrak masih belum mencukupi untuk menghambat pertumbuhan bakteri. Penelitian lebih lanjut perlu dilakukan tentang penggunaan karbopol dan gliserol dengan peningkatan variasi konsentrasi zat aktif ekstrak etanol daun ceremai untuk memperoleh efektivitas yang lebih baik.

\subsection{Pengujian aseptabilitas sediaan gel formula optimal}

Pengujian ini bertujuan untuk mengetahui kelayakan gel antiseptik tangan yang dibuat apakah diterima atau tidak oleh masyarakat. Hal ini diharapkan setiap responden mampu memberikan 
penilaian secara maksimal sesuai dengan yang dirasakan saat gel tersebut dioleskan di kulit. Pengujian ini dilakukan terhadap 20 responden wanita berusia 20-30 tahun.

Parameter yang dinilai dalam penelitian ini antara lain: gel tidak mengiritasi kulit, gel mudah dioleskan, gel mudah dicuci dengan air dan gel tidak lengket. Hasil pengujian mempunyai nilai 4,2 dari skala 5 sehingga menunjukkan bahwa gel yang dihasilkan tidak menyebabkan iritasi pada kulit yaitu tidak menimbulkan rasa panas, gatal, dan warna kemerahan di kulit saat digunakan. Gel tidak mengiritasi kulit dikarenakan $\mathrm{pH}$ sediaan gel yang dibuat sesuai dengan rentang pH kulit yaitu 4,5-6,5 (Aponno, 2014) sehingga sediaan gel aman untuk digunakan.

Gel antiseptik hendaknya mudah dioleskan saat digunakan, hal ini berkaitan dengan homogenitas dan daya sebar sediaan gel. Gel harus mudah dioleskan agar penyebarannya merata dan nyaman saat digunakan. Kriteria mudah dioleskan ini dipengaruhi oleh konsistensi dari gel yang dihasilkan. Hasil pengujian mempunyai nilai 4,05 dari skala 5 sehingga gel yang dihasilkan dapat diterima oleh masyarakat dalam hal kemudahan untuk dioleskan.

Gelling agent yang digunakan juga mempengaruhi kemampuan gel untuk dapat dicuci dengan air. Gelling agent yang digunakan dalam gel antiseptik daun ceremai yaitu hidrogel. Hidrogel umumnya mudah dicuci dengan air. Gel antiseptik harus mudah dicuci dengan air mengingat penggunaannya sebagai alternatif cuci tangan memakai sabun. Hasil uji aseptabilitas gel mudah dicuci dengan air diperoleh nilai 4,2 dari skala 5 sehingga gel ekstrak daun ceremai mudah dicuci dengan air saat digunakan responden.

Gel antiseptik juga harus tidak lengket di kulit, lengket merupakan suatu kondisi yang bisa menimbulkan rasa yang tidak nyaman saat digunakan, hal ini dapat disebabkan karena sediaan tersebut tidak cepat mengering. Hasil uji aseptabilitas gel tidak lengket dikulit diperoleh nilai 3,9 dari skala 5 sehingga menunjukkan gel mudah dicuci dengan air saat digunakan responden.

Tabel 1. Jumlah koloni bakteri

\begin{tabular}{ll}
\hline \multicolumn{1}{c}{ Gel } & Jumlah koloni \\
\hline Gel ekstrak daun ceremai & $\mathbf{7 , 0 8} \pm 0,35$ \\
Gel tanpa ekstrak & $\mathbf{5 6 , 3 \pm 0 , 4 5}$ \\
gel pembanding & $\mathbf{0 \pm 0 , 0 0}$ \\
\hline
\end{tabular}

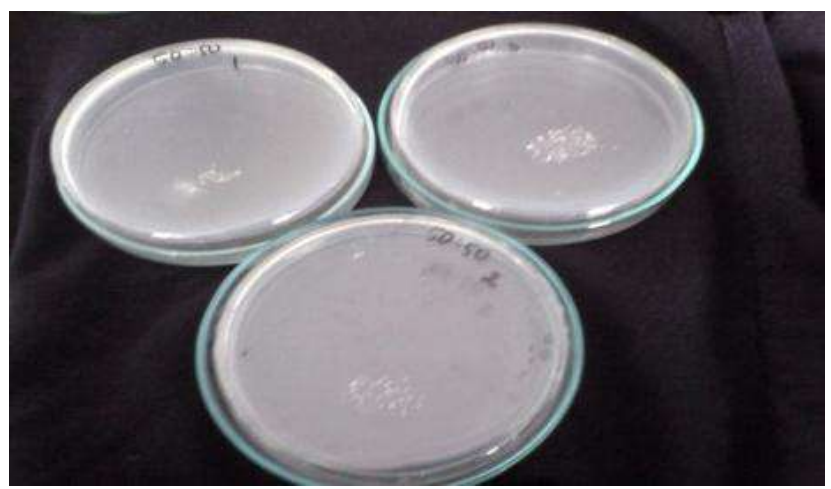

Gambar 1. Gambar Hasil Uji Efektivitas Gel Antiseptik Ekstrak 


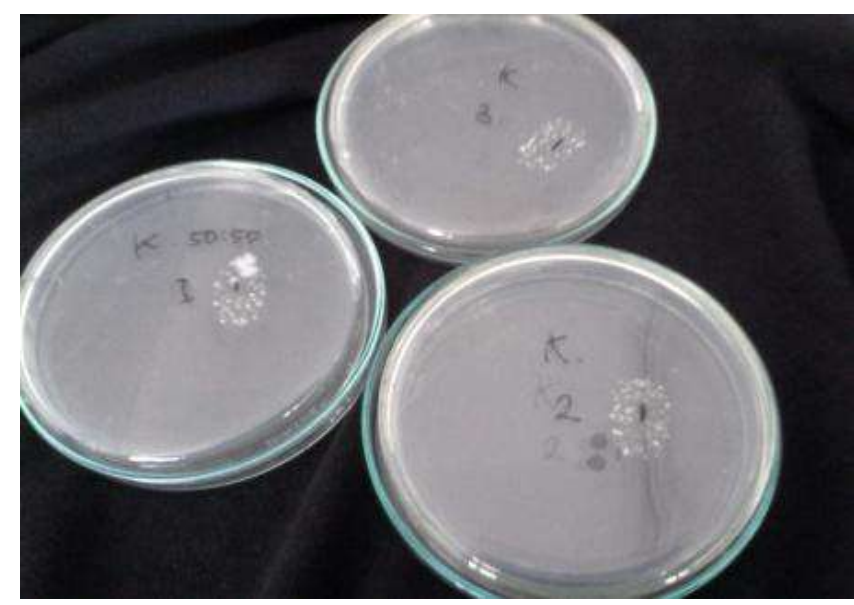

\section{Gambar 2. Gambar Hasil Uji Efektivitas Gel Antiseptik Tanpa Ekstrak}

\section{Kesimpulan}

1. Perbandingan basis karbopol : gliserol (50\%: $50 \%$ ) mampu menghasilkan gel antiseptik ekstrak etanol daun ceremai memberikan kualitas fisik sediaan gel yang paling baik dengan metode Simplex Lattice Design (SLD).

2. Komposisi basis hasil perhitungan Simplex Lattice Design (SLD) menghasilkan gel antiseptik ekstrak etanol daun ceremai dengan kualitas fisik, efektivitas, dan aseptabilitas yang baik.

\section{Ucapan Terimakasih}

Ucapan terimakasih kepada Stikes Farmasi Nasional dan Yayasan Pendidikan Farmasi Nasional Surakarta yang telah membiayai penelitian.

\section{Conflicts of Interest}

"The authors declare no conflict of interest".

\section{Daftar Pustaka}

Ahmad, J., Mir, S.R., Kohli, K., dan Amin, S., 2014. Effect of oil and co-surfactant on the formation of Solutol HS 15 based colloidal drug carrier by Box-Behnken statistical design. Colloids and Surfaces A: Physicochemical and Engineering Aspects, 453: 6877.

Aponno, Jeanly, V., Paulina, Hamidah, 2014, Uji Efektivitas Sediaan Gel Ekstrak Etanol Daun Jambu Biji (Psidium guajava Linn) Terhadap Penyembuhan Luka Yang Terinfeksi Bakteri Staphylococcus aureus Pada Kelinci (Orytolagus cuniculus), Jurnal Ilmiah Farmasi, 3, 3, 283.

Bolton, S. dan Bon, C., 1997. Pharmaceutical Statistics: Practical and Clinical Applications. Dekker Media.

Budiyanti, A., 2009, Uji Aktifitas Antibakteri Ekstrak Etanol Daun Ceremai terhadap S. Aureus dan E.Coli dan Bioautografinya, Skripsi, Universitas Muhammadiyah Surakarta, Surakarta 
Engelina, 2013, Optimasi Krim Sarang Burung Walet Putih (Aerodramus fuciphagus) Tipe M/A dengan Variasi Emulgator sebagai Pencerah Kulit Menggunakan Simplex Lattice Design, Naskah Publikasi, Universitas Tanjungpura : Pontianak.

Garg, A., D. Aggarwal, S. Garg, dan A. K. Sigla, 2002, Spreading of Semisolid Formulation. USA: Pharmaceutical Technology, Pp. 84-104.

Hidayati, Dwi., Wisnu Barlianto dan Puti Fajri, 2012, Uji Efektivitas Ekstrak Daun Ceremai (Phyllanthus acidus (L)) Sebagai Antimikroba Terhadap Bakteri Salmonella thypy secara in vitro, Jurnal Penelitian, Fakultas Kedokteran Universitas Brawijaya

Prasetya, W., 2010, Uji Aktivitas Antijamur Ekstrak Etanol Buah Ceremai ( Phyllanthus acidus (L.) Skeels) Terhadap Candida albicans Dan Tricophyton rubrum, Skripsi, Fakultas Farmasi. Universitas Muhammadiyah Surakarta, Surakarta 